\title{
Pro-Poor tourism strategies in local communities in Uganda: A case study of lake Bunyonyi in Kabale district
}

\section{Kayizzi Moses}

Department of Hospitality, Tourism and Hotel Management, The East African University, Kenya mukayizzi@gmail.com 


\title{
Pro-Poor tourism strategies in local communities in Uganda: A case study of lake Bunyonyi in Kabale district
}

\author{
Kayizzi Moses \\ Department of Hospitality, Tourism and Hotel Management the East African University, Kenya \\ mukayizzi@gmail.com
}

Received: 14/5/2021 Revised: 27/5/2021 Accepted: 21/6/2021 DOI: https://doi.org/10.31559/IJHTS2020.2.1.5

\begin{abstract}
The study examined the effectiveness of pro-poor tourism strategies on local communities in Uganda taking a case study of the Lake Bunyonyi tourist area. Using a descriptive research design, data was collected from a total of 120 community members with the aid of questionnaires. Interviews were also conducted on $10 \mathrm{key}$ informants. The study found that pro-poor tourism strategies that are aimed at enhancing economic benefits to the poor are generally moderately effective as established by the composite mean. This is because the tourism enterprises have employed locals within their ranks, created opportunities for the informal sector and small businesses, boosted household income through home projects such as poultry rearing, bee keeping and fish farming. However, this has been undermined by failure by the enterprises to increased access to market opportunities indirectly to tourism enterprises and to increase community access to investment funds, loans, and micro credit schemes. The study also found that pro-poor tourism strategies that are aimed at enhancing non-financial benefits to the poor are generally moderately effective The strategies have really not succeeded as such in enhancing other non-economic livelihood benefits like; increasing access to health care, health care education for example reproductive health, HIV and malaria prevention; increasing local access to infrastructure and services for example roads, running water, internet, and telephones and improving environmental support. The study found that pro-poor tourism strategies that are aimed at enhancing community participation and partnership are generally moderately effective. The strategies have not fully succeeded in enhancing the participation and involvement of the poor in tourist activities. The study concluded that the pro-poor tourism strategies are only moderately effective in improving the economic benefits to the community, in enhancing non-economic benefits and enhancing of community participation and partnership of the poor in tourist activities.
\end{abstract}

Keywords: Effectiveness; Pro-Poor; Tourism Strategies.

\section{Introduction}

Pro-poor tourism, commonly abbreviated as PPT, is a type of tourism that creates cultural, economic, social, and environmental net benefits for poor persons. Pro-poor tourism is a strategy to the tourism industry as opposed to being a single product or a part of the tourism sector. Rather than growing the sectors' overall size, the strategies for the development of pro-poor tourism are particularly focused on the creation of opportunities for poor persons in tourism. The three key activities necessary are: enhancing economic benefit access for the disadvantaged (through expansion of business and employment options for the disadvantaged, provision of training to help them take advantage of these opportunities, and extension of income above particular recipients to the whole community); tackling the adverse environmental and social consequences of tourism (for example, restricted access to land, coastal areas, and other resources, as well as social upheaval and extortion); and policy/process change (through the establishment of a policy and planning framework that eliminates some of the constraints faced by the poor, increasing the involvement of poor persons in tourist planning and decision-making processes, and the encouragement of private-public partnerships in the development of novel tourism goods).

Pro-Poor Tourism (PPT) increases poor people's net advantages (Ashley, 2002). Traditionally, tourism's impact has been assessed in terms of its contribution to GDP and the number of jobs it has produced. Using a 
multiplier effect approach, the general impact of tourism on the economy is frequently evaluated by observing the impact of tourism expenditures via direct, indirect, and induced spending (Jamieson et al., 2004). Increases in foreign arrivals, duration of stay, occupancy of beds, tourist expenditures, and the value of tourist spending are all common indicators of tourism growth. Despite the consequences of the global financial crisis of 2008, tourism is presently the world's largest and fastest expanding business.

It is commonly believed that economic expansion is the most effective way to reduce poverty (Yin, 2006). It is often accepted that through PPT methods, tourism generates foreign exchange inflows and increases employment. A Demonstration of the benefits of tourism in tackling poverty is difficult due to a scarcity of statistics on the influence of tourism on poverty (Harold, 2006). Instead of being managed as a pro-poor development strategy, the sector has been controlled for foreign exchange gains. PPT can have a substantial role in livelihood stability and the reduction of poverty at the local level, according to Ashley et al., (2001). Employment can be a way out of poverty, and low wages can be a survival tactic, but it is challenging to estimate how much PPT could contribute to national efforts at the reduction of poverty.

Poverty is prevalent in Uganda, and direct approaches to the reduction of poverty are ineffective; hence, 'propoor tourist growth,' or growth that includes the poor in tourism, is required. Tourism is a large economic industry throughout the world, with specifically quick relative growth in poor countries such as Uganda, and hence has the potential to be very vital for pro-poor growth. PPT aims to apply pro-poor growth to the tourist sector by fostering growth patterns that benefit the poor. Despite the rapid growth of the tourism sector in Uganda, poverty rates have remained considerably high in those very areas where tourism takes place such as Lake Bunyonyi in Kabale District, South Western Uganda. The concept of inclusive tourism has been advocated for by a number of private sector actors in the area of Kabale, particularly Lake Bunyonyi.

Despite being a prominent tourist destination in south western Uganda, Lake Bunyonyi, notwithstanding all of its special PPT programs, remains one of Uganda's poorest regions. Due to the spread of numerous preventable illnesses like malaria and HIV/AIDS, poverty is especially widespread among women and young people. Illnesses like these have resulted in $8 \%$ of the population becoming young orphans who have been left to fend for themselves with few sources of obtaining a living or acquiring an education. Several of these disadvantaged youths do not have access to health care and, due to a lack of education, have no way out of poverty. While effort has been made through several initiatives such as the Bunyonyi Safari Resort (BSR) foundation to include the poor into the main stream tourism market, there is evidence that poverty is still a problem in that area. As stated earlier, the concept of inclusive tourism has been advocated for by a number of private sector actors in the area of Kabale, particularly Lake Bunyonyi. Despite this, little has changed in regard to both the economic and non-economic benefits realized due to the initiatives. It is against this background that this paper will focus on establishing the effectiveness of the existing pro-poor tourism strategies utilized in local communities in Uganda with a point of focus on the communities along Lake Bunyonyi in Kabale District.

\subsection{Research Objective}

To assess the effectiveness of pro-poor tourism strategies utilized in local communities at Lake Bunyonyi

\subsection{Research Question}

How effective are the pro-poor tourism strategies in improving the livelihood of poor communities at Lake Bunyonyi?

\section{Literature Review}

\subsection{Pro-Poor Tourism Strategies}

Pro-poor tourist plan is described as a tourism strategy that intends to provide net advantages for the poor to make tourism pro-poor. Rather than boosting the sector's overall size, pro-poor tourism strategies focus explicitly on generating opportunities for the poor inside tourism. Tourism is among the world's most important businesses, accounting for 11 percent of global GDP, employing an estimated 200 million individuals, and carrying approximately 700 million foreign tourists each year - a figure that is anticipated to double by 2022. Developing countries now account for a small portion of the international tourism sector (about 30\%), but this is changing. Since 1990, international tourism arrivals in emerging economies have increased by approximately 9.5 percent annually, in comparison to 4.6 percent globally, necessitating a reassessment of policies that can help local people in these developing countries benefit from tourism.

There are three pro-poor tourism strategies. The first goal of Pro-Poor Tourism is to boost the poor's financial profits. PPT encourages the expansion of local job possibilities as well as the development of local businesses that sell products to the tourism industry. The second strategy is to improve the lives of locals. PPT encourages the expansion of local job possibilities as well as the growth of local businesses that sell products to the tourism industry. The second strategy is to improve the lives of locals. PPT makes services and facilities formerly only available to tourists available to locals. The third tactic of Pro-Poor Tourism is to work together with the poor. This 
entails encouraging poor persons to work in both the public and private sectors. It also entails strengthening policy formulation that encourages impoverished people to participate.

Until recently, those involved in tourism development have not sought to illustrate the effect of tourism on poverty alleviation. Those involved in tourism development tend to concentrate on macroeconomic impact of tourism and its ability to bring progress economically to the disadvantaged individuals and groups in the society instead of coming up with measures and illustrating particular impacts on poverty (Jamieson et al., 2004). Evidence shows that tourism development elevates expatriate and international companies and powerful people in the country while those people in the lower economic and social classes are not employed at all. This leads to generation of low status employment and poor payment. Despite limited emerging indications of the impacts of the ongoing Pro Poor Tourism (PPT) initiatives, PPT interventions are crucial for the poor, where it happens. It is further argued that despite only a handful of the poor or those that are nearly poor taken out of income poverty, a huge number earn critical gap filling income. A huge number also gains non-monetary livelihood benefits. These benefits are very significant though highly varied. They include pride and cultural reinforcement and enhanced access to infrastructure and information among others. Despite some initiatives still being unable to deliver on the ground, there are a few that affect hundreds directly and thousands indirectly (Ashley et Al., 2001).

The Literature on PPT prescribes a wide variety of strategies requiring implementation through a mix of stakeholder input. These strategies are divided into those that generate three different types of local benefits including economic benefits, non- financial livelihood benefits and enhanced participation and partnerships. Table 1: further elaborates Ashley's typology of PPT strategies.

Table (1): Ashley's typology of PPT Strategies

\begin{tabular}{|c|c|c|}
\hline Increased Economic Benefit & Enhanced non-financial Performance & $\begin{array}{l}\text { Enhance } \\
\text { Partnership }\end{array}$ \\
\hline 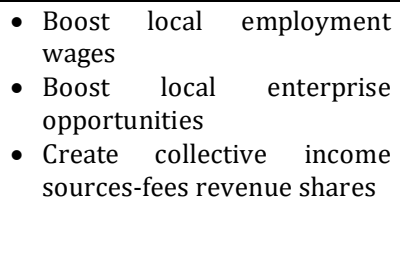 & $\begin{array}{l}\text { - Capacity building training } \\
\text { - Mitigate environmental impacts } \\
\text { - Address competing use of natural } \\
\text { framework resources } \\
\text { - Improve social, cultural impacts } \\
\text { - Increase local access to infrastructure and } \\
\text { services }\end{array}$ & $\begin{array}{l}\text { - } \text { Create more supportive } \\
\text { policy/planning } \\
\text { - Increase participation of the poor } \\
\text { in decision making } \\
\text { - Build pro-poor partnership with } \\
\text { private sector } \\
\text { - Increase flows of information } \\
\text { communication }\end{array}$ \\
\hline
\end{tabular}

Source: adapted from Ashley, (2002)

\subsection{Strategies focused on enhancing Economic Benefit}

An economic benefit of pro poor tourism is an advantage from pro poor tourism initiatives that can be expressed in terms financial amount. This is typically used to evaluate investments and decisions at the level of a nation, region or city Countries promoting tourism experience economic growth rates of over $9 \%$ per year. The first strategy of Pro-Poor Tourism is to increase the financial profits of the poor. PPT promotes the growth of local occupational opportunities and the development of local businesses that supply products for the tourist industry.

These entail businesses that directly sell products to tourist such as crafts, tea shops and guiding. Or they may be businesses that vend inputs such as building materials, fuel and food to tourism operations. Support might vary from marketing and technical support to shifts in procurement strategy (Ashley, 2002). Business opportunities for the underprivileged in the society can be widened by provision of goods and services to the tourism enterprise and its guests (Spenceley \& Seif, 2003). This is only possible through direct vending of goods and services to visitors and it's about the subsistence sector in an economy. The poor could engage in pottering, informal accommodation, stalls selling handcrafts and food and some forms of transport (Yunis, 2004).

Lease fees, revenue shares or donation and equity dividends which are usually established in partnership with tourism operators or government ventures lead to development of collective community income (Ashley, 2002). Tourism can respond to poverty by imposing a charge or tax on its profits or its income with its return aiding poverty alleviation programs. This helps in channeling of resources to those disadvantaged in the society without needing their participation either indirectly or directly. This can be done at either local or national level. In order to avoid discouraging income flows and investment in the long term, approaches involving levies and taxes should be handled with care.

\subsection{Strategies focused on Enhancement of non-financial benefits}

Strategies to enhance other non-monetary livelihood benefits focus on empowerment, capacity building and training. Enhanced social and cultural impacts of tourism, improved accessibility to infrastructure and services; transport, health care, security, road access and water supplies, reduction of environmental impact of tourism on the poor (Ashley,2002). The need for supporting health education, environmental education, access to natural gas and academics is very important (Spenceley \& Seif, 2003). Investment in infrastructure prompted by tourism can significantly benefit the disadvantaged communities. This requires careful planning at an early stage and the local community should be involved (Yunis, 2004). Spenceley and Seif, (2003) further suggested for voluntary donations 
by tourism enterprises and tourists. This may include payments into general charity and programs, such as HIV/AIDs programs by tourists and tour operators or more specific support for projects in destinations visited, philanthropic donations of cash and materials by all tourism enterprises towards local community projects and individuals.

\subsection{Strategies focused on enhancing community participation and partnership}

A pro-poor tourism policy, according to Yin (2006), entails a shift in focus from goals focused on growing total tourism numbers and earnings to ones that emphasize forms of tourism that help the poor. These types of tourism might be labor-intensive, include assistance for the informal sector's participation in the development of tourism, be based on the assets of tourism available to the disadvantaged, and target the development of tourism to the poorest communities. This tourism type should further $\mathrm{b}$ concerned with making sure that the development of tourism does not make worse the issues of the poor by heightening pollution, raising land prices, and limiting access to natural and cultural resources.

According to Ashley (2002), a policy and planning framework that is more supportive will encourage the involvement of the poor, increase their participation in decision making i.e. eensuring that local communities are consulted and have a say in government and private sector tourism decision-making, pro-poor partnerships with the private sector, at the very least: Meetings, feed backs, sharing of novel plans, and increased communication and information flow. This is not participation; rather, it establishes a foundation for future discussion. Advocating for legislative changes, including poor persons in local planning projects, strengthening their voice through producer groups, and building formal and informal ties between the poor and commercial operators might all be part of putting these tactics into action.

\section{Methodology}

Descriptive research design was used for this study. Descriptive study is focused on establishing the what, where and how of a phenomenon (Kothari, 2004). The choice of this design was based on the fact that the researcher was interested on the state of affairs already in existence within the study area and there was no intention of manipulating any variable in the course of the study. The study population consisted of all the households in the communities around Lake Bunyonyi. The population also consisted of key informants who were mainly employees of the tourism establishments in the area. The study used the questionnaires and interview guides for collection of primary data. Interviews were conducted on key informants while questionnaires were used to collect data from the household heads of the selected homesteads. The study used both quantitative and qualitative approaches in analyzing data. Qualitative data from the interviews and open-ended questions from the questionnaire were analyzed thematically while the closed ended questions from the questionnaire were analyzed quantitatively.

Simple random sampling technique was used to select the households to participate in the study. The list of households in Harutindo village was obtained from the local authorities from this sampling frame, 120 households were selected randomly to participate in the study. After randomly selecting the households, the household heads were purposively selected to participate in the study. The key informants were purposively selected to participate in the study because they were believed to be more knowledgeable about the topic under investigation.

Data collection tools included questionnaires and interviews schedules. Primary data was obtained through personal interviews with respondents and by self-administered questionnaires to selected employees of Bunyonyi Safaris Resort project and selected members of the local community at Harutindo market community project. Secondary data was sourced from a review of related literature from journals, published reports, newspapers, textbooks; in house documents for studied research, publications by the Uganda Bureau of Statistics (UBOS) were used. Descriptive statistics like frequency counts, percentages and measures of central tendency like the mean and standard deviation were computed to document the demographic information of the respondents and to document respondent's opinion on the effectiveness of pro-poor tourism strategies and constraints to community participation in tourism activities.

\section{Results}

\subsection{Effectiveness of Pro-Poor Tourism Strategies Utilized.}

\section{Strategies to enhance Economic Benefits}

This section presents the respondents opinion on the effectiveness of strategies to increase economic benefits to the community. The findings were as displayed in table 2 below. 
Table (2): Strategies to Increase Economic Benefits

\begin{tabular}{|c|c|c|c|c|c|c|}
\hline Statements & V.E & $\mathrm{E}$ & $\mathrm{U}$ & I & V.I & Mean \pm S.D \\
\hline & $\mathrm{F}(\%)$ & $\mathrm{F}(\%)$ & $\mathrm{F}(\%)$ & $\mathrm{F}(\%)$ & $\mathrm{F}(\%)$ & \\
\hline Employing community members & $32(26.7)$ & $50(41.7)$ & $5(4.2)$ & $20(16.7)$ & $13(10.8)$ & $2.43 \pm 1.333$ \\
\hline $\begin{array}{l}\text { Creating opportunities for informal sector and small } \\
\text { businesses e.g. craft making, lumbering, basket weaving, } \\
\text { fishing, iron smith, small lodging business etc }\end{array}$ & $38(31.7)$ & $60(50)$ & $6(5)$ & $5(4.2)$ & $11(9.2)$ & $2.09 \pm 1.167$ \\
\hline $\begin{array}{l}\text { Boosting household income e.g. home projects such as } \\
\text { poultry rearing, bee keeping, }\end{array}$ & $42(35)$ & $62(51.7)$ & $2(1.7)$ & $5(4.2)$ & $9(7.5)$ & $1.98 \pm 1.104$ \\
\hline $\begin{array}{l}\text { Increasing access to market opportunities indirectly to } \\
\text { tourism enterprises e.g. campsites, lodges, resorts in the } \\
\text { area }\end{array}$ & $19(15.8)$ & $10(8.3)$ & $5(4.2)$ & $15(12.5)$ & 71(59.2) & $3.91 \pm 1.550$ \\
\hline $\begin{array}{l}\text { Increasing access to investment funds, loans and micro } \\
\text { credit schemes }\end{array}$ & $13(10.8)$ & $20(16.7)$ & $15(12.5)$ & $45(37.5)$ & $27(22.5)$ & $3.44 \pm 1.302$ \\
\hline Increasing access to land use & $0(0)$ & $0(0)$ & $0(0)$ & $84(70)$ & $36(30)$ & $4.30 \pm 0.460$ \\
\hline $\begin{array}{l}\text { Strategies to share revenue/funds from the tourist } \\
\text { enterprises with the community }\end{array}$ & $6(5)$ & $0(0)$ & $0(0)$ & $66(55)$ & $48(40)$ & $4.25 \pm 0.891$ \\
\hline Composite mean & & & & & & 3.20 \\
\hline
\end{tabular}

According to the findings in Table 2, 68.4\% of the respondents noted that the strategy of employing local community members was effective compared to $27.5 \%$ who thought otherwise. The results indicate that the strategy of employing local community members is effective. This implies that the lives of community members at Lake Bunyonyi are likely to improve as a result of employment opportunities that are offered by the tourism businesses in the area. The employment opportunities are likely to improve people's incomes and help them get out of the poverty trap.

A big proportion (81.7\%) of the respondents reported that the strategy of creating opportunities for informal sector and small businesses e.g. craft making, lumbering, basket weaving, fishing, iron smith and small lodging business was effective compared to only $13.4 \%$ who thought otherwise. This indicates that tourism at Lake Bunyonyi has created opportunities for the local community to engage in income generating activities. Such activities lift the poor from the trap of poverty by providing them with incomes that enable them get necessities in life, save, and invest.

The results indicate that majority (86.7\%) of the respondents reported that strategies aimed at boosting household income through home projects such as poultry rearing, bee keeping and fish farming among others were effective compared to only $11.7 \%$ who noted otherwise. This indicates that the strategies employed to boost household income are effective in improving the economic livelihoods of the poor in the communities around Lake Bunyonyi.

A big proportion (71.7\%) of the respondents noted that strategies aimed at increasing access to market opportunities for example campsites, lodges, resorts in the area were not effective compared to only $24.1 \%$ who indicated otherwise. This indicates that the local community has not had access to market opportunities as a result of tourist activities at Lake Bunyonyi. This is a pointer towards ineffectiveness of these strategies. Since the community engages in income generating activities, lack of markets hampers the success of these business ventures.

A large proportion (60\%) of the respondents indicated that strategies aimed at increasing access to investment funds, loans and micro credit schemes were ineffective compared to only $27.5 \%$ who felt otherwise. This indicates that the community has not benefitted from loans and micro credit services and facilities. This is likely to hamper establishment, development, and growth of small-scale businesses in the area and may result into increased poverty among the community members.

All respondent noted that strategies aimed at increasing access to land use were ineffective. This is because most of the land around the lake has been bought off by investors who have established tourist enterprises like restaurants, lodges and camping sites among others. This has denied the community access to use the land for agriculture which is the main economic activity.

A vast majority (95\%) of the respondents reported that the strategies to share revenue/funds from the tourist enterprises with the community were ineffective compared to only $5 \%$ who thought otherwise. This is an indicator that the tourist enterprises at Lake Bunyonyi do not share revenue with the community. This implies that all the resources are siphoned by the proprietors of the tourist establishment without paying any loyalties to the community.

Based on the strategies to increase economic benefits presented on table 2 above, the study further sought to establish their ranks starting from the most effective to the least effective using their mean score, whereby the one with the least mean was regarded to be the most effective amongst them all. The most effective strategy was boosting household income as it had the lowest mean. The rest of the strategies in order of their ranks based on their effectiveness included Creating opportunities for informal sector and small businesses; Employing community members; Increasing access to investment funds, loans, and micro credit schemes; Increasing access to market opportunities indirectly to tourism enterprises; Strategies to share revenue/funds from the tourist enterprises with the community and Increasing access to land use. 
The study further used the composite mean to rate the general effectiveness of the strategies applied to enhance economic benefits to the community members around lake Bunyonyi. The rating scale adopted was as follows (1-1.4: very effective, 1.5-2.4: effective: 2.5-3.4: moderately effective, 3.5-4.4: ineffective, 4.5: very ineffective). From the findings in Table 2, a composite means of 3.20 implied that the effectiveness of the strategies to enhance economic benefits were moderately effective.

\section{Strategies to Enhance Non-Financial Livelihood Benefits}

This section presents the respondents opinion on the effectiveness of strategies to enhance non-financial livelihood benefits to the community. The findings were as displayed in table 3 below.

Table (3): Strategies to Enhance Non-Financial Livelihood Benefits

\begin{tabular}{|c|c|c|c|c|c|c|}
\hline \multirow[t]{2}{*}{ Statements } & V.E & $E$ & $\mathrm{U}$ & I & V.I & \multirow[t]{2}{*}{ Mean \pm S.D } \\
\hline & $\mathrm{F}(\%)$ & $\mathrm{F}(\%)$ & $\mathrm{F}(\%)$ & $\mathrm{F}(\%)$ & $\mathrm{F}(\%)$ & \\
\hline $\begin{array}{l}\text { Increasing access to health care, health care education } \\
\text { e.g. reproductive, HIV prevention, malaria prevention }\end{array}$ & $13(10.8)$ & $20(16.7)$ & $23(19.2)$ & $48(40.0)$ & $16(13.3)$ & $3.28 \pm 1.210$ \\
\hline $\begin{array}{l}\text { Increasing local access to infrastructure and services e.g. } \\
\text { roads, running water, internet, telephones }\end{array}$ & $0(0)$ & $9(7.5)$ & $5(4.2)$ & $58(48.3)$ & $48(40.0)$ & $4.21 \pm 0.839$ \\
\hline $\begin{array}{l}\text { Environmental support, tree planting, swamp and water } \\
\text { bodies e.g. lake Bunyonyi, protection from silting and } \\
\text { pollution }\end{array}$ & $12(10)$ & $15(12.5)$ & $3(2.5)$ & $56(46.7)$ & $34(28.3)$ & $3.71 \pm 1.279$ \\
\hline $\begin{array}{l}\text { Supporting local culture activities e.g. local Bakiga music } \\
\text { (Ebitagururo) or Batwa activities }\end{array}$ & $41(34.2)$ & $52(43.3)$ & $3(2.5)$ & $18(15.0)$ & $6(5.0)$ & $2.13 \pm 1.188$ \\
\hline Composite mean & & & & & & 3.33 \\
\hline
\end{tabular}

According to the results in Table 3, more than half (53.3\%) of the respondents indicated that the strategies to increasing access to health care, health care education for example. Reproductive health, HIV and malaria prevention among others were not effective. This is because despite the existence of such strategies, the community at Lake Bunyonyi is still afflicted by diseases like malaria, tuberculosis and HIV/AIDS among others. This therefore suggests that strategies to improve health care and health care education are not effective.

When asked to rate the effectiveness of strategies for increasing local access to infrastructure and services for example roads, running water, internet, telephones, most (88.3\%) of the respondents the noted that the strategies were ineffective, compared to only $7.5 \%$ who noted otherwise. This is because most of the community members around Lake Bunyonyi do not have access to running water, internet services and electricity. This suggests that the strategy has not improved the lives of the poor in the communities around the lake.

A large proportion (75\%) of the respondents noted that strategies aimed at improving environmental support like; tree planting, protection of swamps and water bodies from silting and pollution were not effective compared to $22.5 \%$ who noted otherwise. This is because no initiative has been undertaken by the stakeholders in the tourism industry to protect the environment in terms of planting trees and protecting swamps. This is an indicator that the businesses put less emphasis on conserving the environment.

Most (77.5\%) of the respondents noted that strategies aimed at supporting local culture activities like local Bakiga music (Ebitagururo) and Batwa activities were effective. This is because the BSR Foundation has made efforts to promote the Bakiga culture through music, dance, drama and art. This is a pointer towards deliberate efforts by the stakeholders around the lake to promote cultural development.

Based on the strategies to enhance non-financial livelihood presented on table 3 above, the study further sought to establish their ranks starting from the most effective to the least effective. The most effective strategy was supporting local culture activities. The rest of the strategies in order of their ranks based on their effectiveness included Increasing access to health care, health care education; Environmental support, tree planting, swamp and water bodies and increasing local access to infrastructure and services. However, it is important to note that, supporting local culture activities strategy was the only non-financial livelihood enhancement strategy that was effective amongst the four, the rest were generally ineffective.

The study further used the composite mean to rate the general effectiveness of the strategies applied to enhance economic benefits to the community members around lake Bunyonyi. The rating scale adopted was as follows (1-1.4: very effective, 1.5-2.4: effective: 2.5-3.4: moderately effective, 3.5-4.4: ineffective, 4.5: very ineffective). From the findings in Table 3, a composite means of 3.33 implied that the effectiveness of the strategies to enhance non-financial benefits were moderately effective.

\section{Strategies to Enhance Community Participation and Partnerships}

This section presents the respondents opinion on the effectiveness of strategies to enhance community participation and partnerships in the Lake Bunyonyi Community. The findings were as displayed in table 4 below. 
Table (4): Strategies to Enhance Community Participation and Partnerships

\begin{tabular}{|c|c|c|c|c|c|c|}
\hline \multirow[t]{2}{*}{ Statements } & V.E & $E$ & $\mathrm{U}$ & $\mathrm{I}$ & V.I & \multirow[t]{2}{*}{ Mean \pm S.D } \\
\hline & $\mathrm{F}(\%)$ & $\mathrm{F}(\%)$ & $\mathrm{F}(\%)$ & $\mathrm{F}(\%)$ & $\mathrm{F}(\%)$ & \\
\hline Increasing access to education & $48(40)$ & $66(55)$ & $0(0)$ & $6(5)$ & $0(0)$ & $1.70 \pm 0.717$ \\
\hline $\begin{array}{l}\text { Increasing access to information e.g. } \\
\text { newspapers, radio news, television etc }\end{array}$ & $0(0)$ & $75(62.5)$ & $39(32.5)$ & $0(0)$ & $6(5)$ & $2.48 \pm 0.744$ \\
\hline $\begin{array}{l}\text { Increasing participation of the poor in decision } \\
\text { making }\end{array}$ & $0(0)$ & $24(20)$ & $15(12.5)$ & $54(45)$ & $27(22.5)$ & $3.70 \pm 1.034$ \\
\hline $\begin{array}{l}\text { Building pro-poor partnerships with private } \\
\text { sector }\end{array}$ & $10(8.3)$ & $12(10)$ & $3(2.5)$ & $68(56.7)$ & $27(22.5)$ & $3.75 \pm 1.161$ \\
\hline $\begin{array}{l}\text { Community organization, cohesion, pride, } \\
\text { women empowerment }\end{array}$ & $0(0)$ & $6(5)$ & $16(13.3)$ & $98(81.7)$ & $0(0)$ & $3.77 \pm 0.530$ \\
\hline Composite mean & & & & & & 3.08 \\
\hline
\end{tabular}

According to Table 4, a vast majority (95.5\%) of the respondents noted that increasing access to education was an efficient strategy for attaining pro-poor tourism in the communities around Lake Bunyonyi. The strategy is perceived to be successful because through the BSR Foundation Lake Bunyonyi Christian Community Vocational Secondary School (BCVS), imparts vocational training skills to the community. This has enabled the poor who did not have access to tertiary institution to gain practical skills which have enabled them start income generating activities or get jobs in the tourist establishments. The finding suggests that the strategy to increase access to education among the community is an effective pro-poor tourism strategy at Lake Bunyonyi.

A big proportion (62.5\%) of the respondents noted that increasing access to information for example, newspapers, radio news and television was an efficient strategy for attaining pro-poor tourism in the communities around Lake Bunyonyi. This is because community access to information through newspapers, radio and television has increased. The different tourist establishments have at least a television set that is accessible to the community. Newspapers and radio are also available in most of these establishments. This suggests that the strategy to increase access to information among the community is an effective pro - poor tourism strategy at Lake Bunyonyi.

More than half $(67.5 \%)$ of the respondents reported that strategies for increasing participation of the poor in decision making were ineffective compared to only $20 \%$ who reported otherwise. This is because community participation in decision making in the tourism sector is low. The key informants revealed that the community was not involved in making key decisions in the tourism business in the area. This portrays that tourism at Lake Bunyonyi is not pro-poor as such; it can be argued that the strategy for ensuring community participation is not effective.

A vast majority (79.2\%) of the respondents indicated that strategies for building pro-poor partnerships with private sector were not effective. This is because no serious partnerships have been built between the community and private sector. Even where such partnerships are built, the communities do not benefit as much as possible. To this effect, one of the key informants reported:

"The tourist enterprises in the area have not made any serious efforts to build serious partnerships with the community. When there is any partnership between the two, the latter benefit more than the community. For example, when they collaborate to make hand crafts and sell them to tourists, the businesses here work as middlemen. They buy cheaply from the community and sell expensively to the tourists".

The findings indicate that there is no meaningful community-private sector partnership at Bunyonyi and as result of the exploitative tendencies, the community may not benefit from such partnerships.

On the effectiveness of strategies to enhance community organization, cohesion, pride and women empowerment, a large proportion (81.7\%) of the respondents reported that the strategy was not effective, while only $5 \%$ answered in the affirmative. This is because there have been no deliberate efforts undertaken to mobilize the community to attain cohesion, pride and women empowerment. Lack of community mobilization for social action is a pointer towards ineffectiveness of these strategies.

Based on the strategies to enhance community participation and partnerships presented on table 4 above, the study further sought to establish their ranks starting from the most effective to the least effective. The most effective strategy was increasing access to education. The rest of the strategies in order of their ranks based on their effectiveness included; Increasing access to information; Increasing participation of the poor in decision making; Building pro-poor partnerships with private sector and Community organization, cohesion, pride, women empowerment. However, it is important to note that, increasing access to education and increasing access to information strategy were the only community participation and partnerships enhancement strategies that were effective amongst the five listed, the rest were generally ineffective.

The study further used the composite mean to rate the general effectiveness of the strategies applied to enhance community participation and partnership among community members around lake Bunyonyi. The rating scale adopted was as follows (1-1.4: very effective, 1.5-2.4: effective: 2.5-3.4: moderately effective, 3.5-4.4: 
ineffective, 4.5: very ineffective). From the findings in Table 4, a composite mean of 3.08 implied that the effectiveness of the strategies to enhance community participation and partnership were moderately effective.

\section{Conclusion}

The findings of this study seem to indicate that pro-poor tourism strategies that are aimed enhancing economic benefits to the poor are somewhat effective. This is because the tourism enterprises have employed locals within their ranks, created opportunities for the informal sector and small businesses, boosted household income through home projects such as poultry rearing, bee keeping and fish farming. However, this has been undermined by failure by the enterprises to increased access to market opportunities indirectly to tourism enterprises and to increase community access to investment funds, loans and micro credit schemes.

The strategies have also not succeeded in enhancing other non-economic livelihood benefits like, increasing access to health care, health care education for example reproductive health, HIV and malaria prevention, increasing local access to infrastructure and services for example roads, running water, internet, and telephones, improving environmental support. The strategies have also failed to fully enhance the participation and involvement of the poor in tourist activities. This is because the current strategies have not enhanced community organization, cohesion and women empowerment and have failed to build pro-poor partnerships with private sector. In order for the strategies to fully benefit the poor, there is need for the stakeholders in the tourism enterprises to adopt a holistic approach to addressing the problems of the poor while putting into consideration the economic, social and environmental needs of the poor. Otherwise, the economic gains made by the strategies are likely to be undermined since development goes beyond addressing the economic needs to addressing the social, cultural and environmental issues that affect the poor.

\section{References}

1. Ashley C. (2002). PPT Working Paper No.10, Methodology for Pro-Poor Tourism Case Studies; Overseas Development Institute.

2. Ashley C., Dilys R., \& Harold G. (2001). Pro Poor Tourism Strategies: Making Tourism work for the poor, Report No 1

3. Harold G, (2006). Measuring and reporting the impact of tourism on Poverty. International center for Responsible Tourism University of Greenwich.

4. Jamieson W., Harold G., \& Edmunds C. (2004). Pro-poor tourism and the challenge of measuring impacts Contribution of tourism to poverty alleviation, For Transport Policy and Tourism Section, Transport and Tourism Division UN ESCAP.

5. Kothari C.R, (2004). Research Methodology, Methods, and techniques (second revised edition).

6. Spenceley A. \& Seif J. (2003). PPT working paper No 11; Strategies, Impacts and Costs of Pro-Poor Tourism Approaches in South Africa

7. Yin, S. (2006). The impact of Tourism on Rural livelihoods, Tonle Bati, Ta Keo, Cambodia, RUPP, Phno Penh.

8. Yunis E, (2004). Sustainable Tourism on Poverty Alleviation; Paper presentation World Bank- ABCDE Conference- Europe. 